Volume 16 - Número 1 - jan/jul de 2021

\title{
A VARIÁVEL SEXO/GÊNERO EM ESTUDOS SOCIOLINGUÍSTICOS: UM PANORAMA DAS TRÊS ONDAS
}

\author{
THE SEX/GENDER VARIABLE IN SOCIOLINGUISTIC STUDIES: \\ A PANORAMA OF THE THREE WAVES
}

\begin{abstract}
André Luiz Souza-Silva ${ }^{1}$ Rubens Marques de Lucena²

RESUMO: O presente artigo tem o objetivo de apresentar e refletir sobre dados de três pesquisas sociolinguísticas de cunho variacionista já realizadas, com a finalidade de exemplificar os estudos e interesses das "três ondas" de investigação da Sociolinguística, uma vez que essa área envolve variadas abordagens e desenvolve pesquisas sob uma égide comum: língua e sociedade são inseparáveis. Dito isso, este trabalho é de natureza qualitativa e de caráter bibliográfico, apresentando os estudos de primeira onda como mais estatísticos e binários, os de segunda onda como etnográficos e os de terceira onda como estilísticos, desprendendo-se de padrões binários limítrofes. Essas considerações se fazem possíveis à luz das vozes de Labov (2008), Bagno (2007, 2017), Eckert \& McConnell-Ginet (2010), Freitag (2015), entre outros.

PALAVRAS-CHAVE: Sociolinguística. Primeira, segunda e terceira onda. Variável sexo/gênero.

ABSTRACT: This paper aims to present and reflect on data from three previous variationist sociolinguistic research, with the purpose of exemplifying studies and interests of the "three waves" of research in Sociolinguistics, since this area involves various approaches and develops research under a common assumption: language and society are inseparable. That said, this study is based on qualitative and bibliographic grounds, presenting the first wave studies as more statistical and binary, the second wave as ethnographic and the third wave as stylistic, detaching from binary patterns. These considerations are made possible in light of Labov (2008), Bagno (2007, 2017), Eckert \& McConnell-Ginet (2010), Freitag (2015), among others.
\end{abstract}

KEYWORDS: Sociolinguistics. First, second and third wave. Variable sex/gender.

\section{Introdução}

A corrente de estudos da Sociolinguística apresenta uma premissa fundante: a relação indissociável entre língua e sociedade. A partir disso, os estudos sociolinguísticos variacionistas, considerados estudos clássicos da área, passaram a ser desenvolvidos à luz dos postulados de William Labov, linguista estadunidense. As intenções de estudo da área iniciaram na década de 60 do século passado, compreendendo que o processo de variação e mudança linguística são próprios do sistema linguístico, considerando não só que as línguas são mutáveis em contexto diacrônico, mas também sincrônico.

Com o passar dos anos, e com a consolidação dos estudos sociolinguísticos, a área passa a considerar outras faces no processo de análise da língua, estabelecendo outros aspectos como interessantes para o campo. Assim, a Sociolinguística passou a ser, panoramicamente, dividida em "três ondas" de estudos. Dito isso, este artigo tem o objetivo de analisar dados de três pesquisas sociolinguísticas de pós-graduações brasileiras - selecionadas a partir de leituras prévias que já compõem os materiais de estudo e pesquisa dos autores ${ }^{3}$ - para exemplificar a

\footnotetext{
${ }^{1}$ Mestrando em Linguística pela Universidade Federal da Paraíba (PROLING/UFPB/CAPES). Atualmente, está professor do Departamento de Letras e Artes da Universidade Estadual da Paraíba (UEPB/DLA)

${ }^{2}$ Doutor em Linguística e professor associado do Departamento de Letras Estrangeiras Modernas e do Programa de Pós-Graduação em Linguística da Universidade Federal da Paraíba (UFPB/DLEM/PROLING).

3 Agradecimento a CAPES pela bolsa concedida (2020-2022), possibilitando maior dedicação aos estudos, à pesquisa e no que diz respeito às atividades promovidas pelo programa ao qual estou associado.
} 
variável sexo/gênero, sendo uma pesquisa destinada a cada uma das "três ondas". Paralelo a isso, faz-se necessário refletir sobre essas divisões nos estudos sociolinguísticos.

Nessa direção, entende-se que este artigo contribui para a exploração e exemplificação das pesquisas sociolinguísticas a partir das "três ondas", uma vez que são escassos os trabalhos com este objetivo de exemplificação. Ademais, é perceptível, no contexto brasileiro, um maior interesse pelos estudos sociolinguísticos de primeira onda, sendo os de segunda onda pouco investigados e os de terceira onda ainda tímidos. Para tanto, a partir das caracterizações de Paiva (2019), o trabalho é de natureza qualitativa e caráter bibliográfico.

O artigo estrutura-se em seções, sendo a seção 2 para as discussões que fundamentam a Sociolinguística e seus interesses; já a 3 focaliza a variável sexo/gênero, problematizando as "três ondas"; a seção 4 traz à baila alguns dados de pesquisas stricto sensu para exemplificar e refletir sobre a variável em questão junto aos estudos sociolinguísticos; adiante, as considerações finais, seguidas das referências que ancoram as reflexões contidas nestes escritos.

\section{Sociolinguística: enlaces e interesses}

A Sociolinguística é uma subárea da linguística que se ocupa do estudo da variação e mudança linguística, investigando a língua em uso real, uma vez que se interessa pelo viés mais pragmático das estruturas linguísticas, considerando fatores sociais como variáveis, as quais corroboram a variabilidade e mudança de toda e qualquer língua natural. Assim, é uma área interdisciplinar (MOLLICA, 2015 [2004]), haja vista suas reflexões e observações diante de fatos heterogêneos da linguagem em uso.

A área se desenvolveu no espaço estadunidense, durante a década de 1960, tendo William Labov como seu precursor, se não de toda a área, de seu campo mais conhecido: os estudos variacionistas. É válido ressaltar que a nomenclatura "sociolinguística" é problemática, pois leva a pensar ou considerar que exista alguma vertente que desconsidere o fato social, pois, apesar de áreas mais formalistas darem menos ênfase a esse fator, ele não é desconsiderado. Nesse sentido, Labov (2008 [1972]) ressalta:

Por vários anos, resisti ao termo sociolinguística, já que ele implica que pode haver uma teoria ou prática linguística bem-sucedida que não é social [...] Apesar de um considerável volume de atividade sociolinguística, uma linguística socialmente realista parecia uma perspectiva remota nos anos de 1960. (LABOV, 2008, p. 13, grifo do autor)

Mediante o exposto, e apesar de considerar o termo pouco adequado, a Sociolinguística construiu suas bases em um aparato teórico-metodológico positivo para a investigação que se interessa pela relação entre língua e sociedade. Ademais, Labov (2008) indica que todos os linguistas reconhecem que a língua é um fato social, mas não são todos que dão destaque a esse fato, uma vez que "quando os linguistas escrevem sobre mudança linguística, encontramos um grau muito diferente de preocupação com o contexto social em que essas mudanças ocorrem" (LABOV, 2008, p. 302).

Portanto, a depender da gama de informações extralinguísticas que se tenta incluir ou excluir, poderemos afirmar a concepção de língua que cada profissional tem e a importância que dá para a mudança linguística (LABOV, 2008). Assim, identifica-se a relevância dos estudos da área apesar dos entraves de sua nomenclatura. Dito isso, é possível identificar a relevância que os fatores sociais e culturais terão em relação à análise e reflexão que se faz sobre a interação com linguagem e pela linguagem.

Nesse sentido, a Sociolinguística se firma interdisciplinar. Afinal, para explicar os mais variados fenômenos linguísticos, lança mão de conhecimentos da Sociologia, da Psicologia Social, da Filosofia, das Ciências Políticas, etc. Desse modo, é possível identificar um 
Volume 16 - Número 1 - jan/jul de 2021

continuum de investigações no campo, o qual vai do macro (mais social) ao micro (mais linguístico), como explica Bagno (2017):

[...] a sociolinguística variacionista, inaugurada por W. Labov, se aproxima bem mais do extremo linguístico desse continuum, uma vez que recorre aos fenômenos de ordem social para explicar os fenômenos linguísticos, interessada como é sobretudo nos processos de mudança linguística - nessa abordagem, portanto, o foco estaria em como a língua é configurada pela sociedade. No outro extremo talvez se pudesse situar a sociologia da linguagem, que investiga as consequências sociais, culturais, políticas etc. da variação e da mudança, ou seja, como a sociedade é configurada pela(s) línguas(s). (BAGNO, 2017, p. 426, grifos do autor)

A partir do exposto, consideramos que a Sociolinguística é um campo amplo de investigações, o qual se configura e reconfigura considerando a heterogeneidade linguística e social, identificando tanto os processos de mudança e variação das estruturas linguísticas quanto as mudanças e diversidade sociais existentes que se coadunam com o uso da língua, uma vez que tanto entende a língua como configuradora da sociedade quanto configurada por essa última. Nesse sentido, é possível observar interesses diferentes a depender dos objetivos de cada pesquisa e pesquisador, como veremos a seguir.

\section{A variável sexo/gênero com foco nas três ondas}

Quando se realiza uma pesquisa de vertente sociolinguística, estabelece-se tanto variantes linguísticas quanto variáveis sociais para poder construir uma metodologia adequada para a captação do fenômeno linguístico. Para tanto, algumas variáveis se destacam:

Quadro 1 - Algumas variáveis extralinguísticas

$>$ Grau de escolarização: é proveniente do acesso à educação formal, ou seja, o acesso à leitura e à escrita em letramento escolar;

$>$ Idade: jovens falam diferente de idosos e que crianças falam diferente de adultos;

$>$ Ocupação: em relação à profissão que o falante exerça, seu vocabulário será distinto;

$>$ Origem geográfica: pois há variedade linguística de um lugar para outro, como é o caso de comunidades rurais e urbanas, bem como entre municípios;

$>$ Redes sociais: que é a partilha de comportamentos linguísticos, assim, há semelhança entre as variedades linguísticas que utilizo junto aos meus familiares, por exemplo;

$>$ Status socioeconômico: se faz pelo nível de renda dos falantes e acesso a bens culturais;

$>$ Sexo/gênero: pelo fato de homens terem um falar distinto de mulheres, bem como transgêneros poderem apresentar variedades distintas de cisgêneros, por exemplo.

Fonte: elaborado com base em Bagno (2007).

É interessante focalizar a variável sexo/gênero, uma vez que é ela quem será discutida com ênfase neste trabalho. Faz-se necessário saber o seguinte:

[...] essa variável tem sido bastante problematizada pelos sociolinguistas atuais, uma vez que a diversidade sexual e de gênero tem indicado a necessidade de se refletir pensando além dos binarismos, como homem $\mathrm{x}$ mulher; heterossexual $\mathrm{x}$ homossexual, uma vez que essa questão extralinguística é fluída. (SILVA, 2020, p. 35) 
Volume 16 - Número 1 - jan/jul de 2021

As chamadas "três ondas" de investigação da Sociolinguística se situam, em sentido histórico e político, a partir das fases/gerações do(s) Movimento(s) Feminista(s), especialmente quando se trata das investigações acerca da variável sexo/gênero. Os estudos de Lakoff (2010 [1973]), por exemplo, contribuíram para os enlaces das problematizações entre linguagem, gênero e sexualidade, onde a autora indica que "somos usados pela linguagem tanto quanto a usamos" (LAKOFF, 2010, p. 13).

Nesse sentido, é preciso considerar que a linguagem se constitui dos itens linguísticos que desejamos expressar, mas também se faz pela forma que selecionamos para enunciá-los (LAKOF, 2010). Dito isso, faz-se necessário explicar os desdobramentos históricos do(s) Movimento(s) Feminista(s) e sua relação com os estudos sociolinguísticos. Na primeira fase, rechaça-se a ideia da mulher como propriedade e domínio masculino. Para tanto, essa geração do movimento se faz pelas seguintes ideias:

A partir da influência dos valores socialistas, defendiam a ideia de que o sistema de domínio estabelecido pela sociedade masculinizada era a principal causa da opressão sofrida pelas mulheres e, por isso, desejavam construir um mundo novo onde todos/as estariam livres das correntes do patriarcado. (ANDRADE; SANTOS, 2016, p. 25)

Mediante o exposto, a primeira fase é o embrião do movimento, a qual defende a igualdade de direitos civis, políticos e educativos, os quais eram resguardados e legitimados para homens. Linguisticamente, os estudos de primeira onda, de acordo com Freitag (2015), buscam identificar padrões regulares de distribuição de variantes linguísticas, por meio da coleta de dados em comunidades de fala estratificadas a partir de categorias sociodemográficas extensas, como é o caso do estudo da estratificação do /r/ no inglês de Nova York, feito por Labov na década de 1960. Já na segunda fase do movimento, caracteriza-se o "feminismo da diferença", em que é necessário pensar a diferença em detrimento da igualdade. Nessa direção, compreende o seguinte:

[...] não mais se pensava que para eliminar a desigualdade social, as mulheres deveriam ser iguais aos homens, mas se caracterizava por uma atitude separatista em relação ao universo masculino; esperavam conquistar espaços e fazer perceber e respeitar em suas singularidades. (ANDRADE; SANTOS, 2016, p. 28)

A partir disso, vê-se a necessidade de debater a relação igualdade-diferença, identificando equivalências e subjetividades. Em relação à análise linguística, Freitag (2015) afirma o seguinte:

Estudos de segunda onda também tomam como amostra comunidades de fala e visam identificar padrões regulares de distribuição de variantes linguísticas em abordagem quantitativa. No entanto, diferem da outra abordagem por seguirem uma perspectiva de base mais etnográfica, com coletas de dados que requerem maior envolvimento com a comunidade e selecionam categorias sociodemográficas mais abstratas, não identificáveis em uma coleta rápida, como o julgamento de pertencimento à comunidade, valores, atitudes, etc. Exemplo é o estudo laboviano do inglês afroamericano em Nova York. (FREITAG, 2015, p. 37)

Nesse sentido, salienta-se que os estudos brasileiros de Bortoni-Ricardo se caracterizam como de segunda onda, como é o caso da obra Do campo para a cidade: estudo sociolinguístico de migração e redes sociais (2011 [1985]). Por fim, a terceira onda passa a ampliar horizontes, 
uma vez que o advento da categoria "gênero" leva o feminismo a outro nível e as discussões passam a considerar a variável gênero como construto social, não limitando os atos de ser "mulher" e/ou "homem", por exemplo, como algo puramente biológico. Nessa fase, a diferença em si é um marcador de diferenças e as experiências das lutas sociais se tornaram diversas e múltiplas, focalizando "[...] a existência de diferenças coletivas significativas entre as mulheres", como expressam Andrade \& Santos (2016, p. 35, grifos das autoras).

Os estudos sociolinguísticos de terceira onda, conforme Freitag (2015), diferenciam-se porque invertem a ordem da problematização, uma vez que não se busca mais uma correlação entre o padrão linguístico e as categorias sociais. Assim, passa a identificar as categorias sociais que atuam no padrão linguístico. A partir disso, vê-se uma retomada do significado social da variação, interessando-se mais pela prática linguística do que pela estrutura. Essas investigações adotam como unidade comunidades de práticas ao invés de comunidades linguísticas, o que permite investigar "[...] o papel do indivíduo, em termos de hierarquia, inovação e adesão a variáveis linguísticas" (FREITAG, 2015, p. 37).

Dito isso, é válido ressaltar e explicar que cada onda também pode se interessar por sujeitos $\mathrm{LGBT}+{ }^{4}$, ressaltando que nem sempre é produtivo na primeira onda. Entretanto, é possível realizar um estudo em larga escala, como os estudos labovianos, buscando por generalizações, mas o que pode ser complicado, uma vez que as identidades sexuais são múltiplas e podem não fornecer dados que concretizem a realidade linguística pela qual o sociolinguista tradicional se interessa, uma vez que essa abordagem trabalha com categorias fechadas.

Numa abordagem de segunda onda, o caráter etnográfico fica em evidência, pois interessa-se pela verticalização e particularidade de determinada comunidade. Assim, é possível estudar a linguagem de sujeitos LGBT + , acompanhando seu cotidiano em contexto profissional, familiar e de amigos, buscando identificar padrões de uso linguístico. Nessa vertente, as categorias binárias se desfazem mais, pois podem privilegiar apenas a comunidade em questão, sem, necessariamente, precisar associar aos padrões cis-heteronormativos, uma vez que a segunda onda se interessa pelas singularidades.

Em relação à terceira onda, a abordagem é mais indexicalizada, buscando compreender determinados comportamentos linguísticos. Assim, seria possível investigar a fala, as crenças e valores associados a determinadas variantes linguísticas, considerando apenas a análise dos falares de sujeitos LGBT+. Ademais, Freitag (2015) ressalta que a terceira onda também focaliza questões quantitativas ao centralizar a variedade estilística como objeto de investigação. Por isso, a terceira onda focaliza as subjetividades e os marcadores de diferença de forma plural.

Nessa última abordagem - onde o controle da variável sexo/gênero deve ser mais refinado - compreendemos que é possível instaurar uma abordagem mais qualitativa do que quantitativa. Na realidade, puramente qualitativa, interessando-se mais pelas crenças, valores, estigmas, prestígios, discriminação e empoderamento a partir do senso comum que os falantes apresentam sobre si, sobre seus pares e suas variantes linguísticas. Afinal, "[...] se a Sociolinguística tem como premissa, em tendência ampla, o estudo da relação entre língua e sociedade, precisa considerar que a sociedade muda; se a sociedade muda, as explicações do modelo teórico-metodológico deveriam, também, mudar [...]" (FREITAG, 2015, p, 18).

E essa abordagem permanece alinhada à terceira onda tomando a "comunidade de prática" como parte da metodologia, uma vez que "[...] define uma comunidade pelo seu

\footnotetext{
${ }^{4}$ O modelo ALGBTQI+ (assexuados, lésbicas, gays, bissexuais, transexuais, travestis, queer, intersexuais e mais) tem sido difundido com a finalidade de representar maior pluralidade de identidades sexuais e de gênero. Neste trabalho, assume-se o uso de LGBT+ considerando "+” como representativo de outros gêneros e sexualidades.
} 
Volume 16 - Número 1 - jan/jul de 2021

engajamento social [...]" (ECKERT; McCONNELL-GINET, 2010 [1992], p. 103). Para essa abordagem qualitativa, compreende-se e apoia-se no seguinte:

\begin{abstract}
Os sujeitos que cruzam as fronteiras de gênero e sexualidade talvez não 'escolham' livremente essa travessia, podem se ver movidos para tal por muitas razões, podem atribuir a esse deslocamento distintos significados. Podem, tal como quaisquer outros viajantes, ver sua travessia restringida, repudiada ou ampliada por suas marcas de classe, de raça ou por outras circunstâncias de sua existência. Sua viagem talvez possa se caracterizar como um ir e voltar livre e descompromissado ou pode se constituir num movimento forçado, numa espécie de exílio. (LOURO, 2020, p. 18)
\end{abstract}

Essa questão dos "viajantes" se faz para que se compreenda que sujeitos LGBT+ cruzam caminhos, por opção ou não, que os colocam em uma posição diferente na sociedade, haja vista serem alvos da LGBTfobia. Isso não é apenas um dado, mas um fato que se materializa nas práticas linguísticas desses sujeitos, uma vez que também utilizam a linguagem como instrumento de ataque/defesa (PRETI, 1984), quando a empunham em suas batalhas por sobrevivência. Além disso, “[...] é através do exercício da linguagem que se definem identidades" (ABAURRE, 2006, p. 17).

\title{
3 Discussões à luz de dados sociolinguísticos
}

Nesta seção, far-se-á uma explanação de dados de pesquisas sociolinguísticas brasileiras, com a finalidade de exemplificar coletas, dados e análises, sendo uma investigação para cada uma das três ondas. Para tanto, selecionamos três pesquisas de pós-graduações stricto sensu brasileiras. Para a primeira onda, foram selecionados dados da pesquisa de mestrado de Alexandre Monte: Concordância verbal e variação: uma fotografia sociolinguística da cidade de São Carlos defendida em 2007 e institucionalizada na Universidade Estadual Paulista Júlio de Mesquita junto ao Programa de Pós-graduação em Linguística e Língua Portuguesa. Dito isso, em artigo mais recente, Monte (2019) retorna aos dados, controlando as variáveis grau da escolaridade e sexo/gênero, sobre a produção o autor determina o seguinte:

[...] retomamos os resultados obtidos com as variáveis escolaridade e sexo/gênero em duas pesquisas sociolinguísticas com dados da cidade de São Carlos/SP/Brasil. Estudamos o uso variável da concordância verbal de terceira pessoa do plural com base nos princípios teóricos e metodológicos da Teoria da Variação e Mudança Linguística [...]. Nas duas pesquisas, as variáveis sociais escolaridade e sexo/gênero se mostraram estatisticamente significativas. (MONTE, 2019, p. 89)

A partir dos postulados da Sociolinguística, mais especificamente os da Variação e Mudança, o autor trabalha com a análise de dados de dois estudos realizados em São CarlosSP, sendo um de 2007 e outro de 2012. Monte (2019) explica que, no estudo de 2007, das 1.000 ocorrências no corpus, 753 (75\%) não exibiram a marca formal de plural nos verbos e apenas 247 (25\%) apresentaram tal marcação. Já a amostra de 2012 é composta por 1.422 ocorrências de $3^{\text {a }}$ pessoa do plural, sendo 686 ocorrências $(48,2 \%)$ com a marca formal de plural nos verbos e $736(51,8 \%)$ ocorrências sem a desinência. Abaixo, a tabela expõe os resultados alcançados por meio de controle estatístico da variável sexo/gênero: 
Volume 16 - Número 1 - jan/jul de 2021

Tabela 01 - variável sexo/gênero e frequência uso

\begin{tabular}{|l|l|c|c|c|}
\hline \multirow{2}{*}{ Fatores } & \multicolumn{2}{|c|}{ Corpus de 2012 } & \multicolumn{2}{c|}{ Corpus de 2007 } \\
\cline { 2 - 5 } & Frequência & PR & Frequência & PR \\
\hline Masculino & $323 / 708=45,6 \%$ & 0,410 & $121 / 488=25 \%$ & 0,45 \\
\hline Feminino & $363 / 714=50,8 \%$ & 0,589 & $126 / 492=26 \%$ & 0,55 \\
\hline Total & $\mathbf{6 8 6} / \mathbf{1 . 4 2 2}=\mathbf{4 8 , 2} \%$ & & $\mathbf{2 4 7 / 9 8 0}=\mathbf{2 5 \%}$ & \\
\hline \multicolumn{6}{|c|}{ Fonte: Monte (2019, p. 96$).$}
\end{tabular}

A partir de tais resultados, Monte (2019) defende a hipótese clássica de que mulheres favorecem a variedade linguística de prestígio, uma vez que "[...] as mulheres da amostra demonstraram mais sensibilidade à variante de prestígio. Os homens empregaram menos as marcas de plural nos verbos $(0,410)$ do que as mulheres (0,589)" (MONTE, 2019, p. 96). Nesse sentido, as análises do autor corroboram o que pesquisas de primeira onda já têm feito desde suas bases: comprovam a atitude mais conservadora das mulheres, quando estão em questão uma variante de prestígio e uma variante estigmatizada.

A categorização selecionada e a análise realizada pelo autor favorecem a abordagem de primeira onda pelo seguinte: "os estudos dessa tendência forneceram um amplo retrato das variáveis linguísticas usadas pelas comunidades de fala definidas geograficamente ao redor do mundo [...]" (VELOSO, 2014, p. 1742). Sobre a abordagem de Monte (2019), é importante ressaltar que a atualidade da pesquisa do autor oportuniza a reflexão sobre o controle da variável sexo/gênero, pois ainda que sua pesquisa seja de primeira onda, associando-se mais com a visão biológica de sexo, o autor defende, à luz das reflexões de Freitag (2015), que é preciso "[...] ter uma postura moderada ao interpretar esses resultados" (MONTE. 2019, p. 97).

Para a segunda onda, é interessante a exposição de dados da pesquisa de mestrado de Rafael Ferreira Coelho, defendida em 2006 - institucionalizada na Universidade de São Paulo junto ao Programa de Pós-graduação em Linguística - e intitulada: É nóis na fita! Duas variáveis linguísticas numa vizinhança da periferia paulistana. Estudo sociolinguístico de caráter etnográfico, tendo o seguinte objetivo:

[...] demonstrar que a variedade falada nos bairros de periferia em São Paulo apresenta duas tendências contrárias às outras variedades: (a) a gente não constitui necessariamente o pronome favorito na comunidade e (b) o fenômeno de perda de marca morfológica tende a generalizar-se para a expressão da primeira pessoa do plural no verbo [...]. (COELHO, 2006, p. 08)

Para tal, o autor adotou as entrevistas como instrumento de coleta sociolinguística, mas também realizou um período de observação etnográfica, com a finalidade de identificar os variados status sociais atribuídos aos sujeitos que frequentam a comunidade investigada - bairro Brasilândia (zona norte de São Paulo). Assim, obteve 24 entrevistas, alinhadas com a observação que, segundo Coelho (2006), foi realizada em duas etapas, numa foram feitas caminhadas pelo bairro, para observar os limites da vizinhança, as pessoas nas ruas e os espaços físicos da paisagem; noutra, a partir de categorias sociais relevantes para a análise sociolinguística, observou pessoas que frequentam uma praça local da vizinhança.

Essa abordagem é de segunda onda porque desenvolve pesquisas que "[...] fornecem um retrato local das variáveis linguísticas, no sentido em que estas, situadas em comunidades menores, assumem valor social relativo à dinâmica local" (VELOSO, 2014, p. 1743). Inclusive, os estudos que fazem referência à segunda onda são mais escassos no Brasil, onde os estudos de primeira onda são bem mais difundidos. Além disso, os estudos sociolinguísticos de método etnográfico são mais longitudinais, exaustivos e densos o que requer um maior controle das variáveis sociais, como o caso de sexo/gênero. Sobre a problemática da questão, Coelho (2006) explica o seguinte sobre seus informantes: 
Volume 16 - Número 1 - jan/jul de 2021

[...] entre os nossos 24 informantes entrevistados não há a mesma quantidade de homens e mulheres. Por exemplo, entre os mais idosos, há poucos homens, e eles são todos membros da associação de moradores. Em outras palavras, não há homens com mais de 30 anos de idade representantes de outros grupos na comunidade. (COELHO, 2006, p. 79)

Assim, o pesquisador necessita controlar as "categorias" de análise a partir de seu contexto de pesquisa já estabelecido, buscando maneiras de revelar padrões sociolinguísticos sem misturar papéis sociais ou acabar criando "pontes" muito distantes entre os participantes da pesquisa, o que irá também comprometer a observação etnográfica. Para resolver a questão, o autor decidiu o seguinte:

[...] a análise da variável gênero/sexo foi feita com um número reduzido de informantes, e separadamente. Foram feitas duas divisões, de acordo com o gênero/sexo do informante e com a classe social: uma para opor diferenças de gênero entre os setores mais prósperos da vizinhança, e outra para opor homens mais jovens a 'mães solteiras'. (COELHO, 2006, p. 79)

A partir do controle da variável, o autor alcançou os seguintes dados:

Tabela 02 - variável sexo/gênero em estudo etnográfico

\begin{tabular}{|l|c|c|c|}
\hline \multirow{2}{*}{ Fatores } & \multicolumn{3}{c|}{ Nóis } \\
\cline { 2 - 4 } & No./total & \% & Peso [relativo] \\
\hline Homens casados com trabalho & $8 / 80$ & 10 & 0,128 \\
\hline Mulheres casadas e donas de casa & $44 / 87$ & 50 & 0,634 \\
\hline Homens solteiros e desempregados & $76 / 92$ & 82 & 0,884 \\
\hline Mães solteiras com trabalho & $40 / 142$ & 28 & 0,361 \\
\hline \multicolumn{2}{|c}{ Fonte: Coelho (2006, p. 124). } \\
\hline
\end{tabular}

De acordo com Coelho (2006), a forma "a gente" é mais utilizada pelos homens da classe trabalhadora mais remunerada e de posição mais estável, os quais são, em sua maioria, os pais de "famílias estruturadas" com maior prestígio na vizinhança. Já as mulheres que não trabalham fora, que são dessas "famílias estruturadas", utilizam mais frequentemente o pronome normativo. As mulheres que dão mais preferência ao pronome "a gente" são as mães solteiras que trabalham fora do bairro. É possível que essas falantes comecem a usar mais o "a gente" por terem contato com falantes de classe média, uma vez que trabalham como faxineiras ou empregadas domésticas. Elucidados os dados, o autor conclui o seguinte:

Portanto, o maior emprego de a gente ocorre somente na fala daqueles que trabalham fora do bairro e que possuem contatos com falantes de diferentes classes sociais. Os homens desempregados, que são os mais jovens, são aqueles que não alteram o uso pronominal mais característico dos bairros de periferia. (COELHO, 2006, p. 125, grifo do autor)

Mediante o exposto, é possível identificar a relevância da abordagem etnográfica e como oportuniza leituras mais apuradas da dinâmica social que envolve o uso linguístico. Logo, "[...] os estudos etnográficos trouxeram-nos uma visão mais clara de como as formas de falar estão imbuídas de significado local" (ECKERT, 2005 apud VELOSO, 2014, p. 1743).

Por fim, para exemplificar os estudos da terceira onda, recorre-se à pesquisa de Rafaela Veloso, tese de doutorado defendida em 2016, associada ao Programa de Pós-graduação em Linguística da Universidade Federal da Paraíba e intitulada: A fala de mulheres lésbicas em comunidades de práticas: estilo, gênero e identidade. Em 2017, a autora publica artigo, fruto da tese, sobre as tendências inovadoras que a Sociolinguística tem traçado e seu interesse pelo 
Volume 16 - Número 1 - jan/jul de 2021

estudo da variação estilística. De acordo com Veloso (2017, p. 232), o objetivo do trabalho é o seguinte: "percorrer as principais abordagens da Sociolinguística para abordar o seu caminho mais atual, suas reflexões e implicações para o tratamento do estilo no estudo da variação linguística".

Para tanto, Veloso (2017), a partir de uma análise qualitativa e interpretativa, examina uma amostra composta por dados de áudio obtidos através de gravação da fala das quatro participantes em ambiente de trabalho e em ambientes de lazer. Esses dados foram gravados livremente pelas próprias informantes e foram registradas mais de dezessete horas de gravação. Sobre a análise dos dados, a pesquisadora diz o seguinte:

Visto que não elegemos uma variável linguística específica para a apreciação dos dados, a análise se concentrou nos trechos das gravações em que as falantes desenvolveram algum discurso metalinguístico sobre o uso de uma forma linguística, usaram algum recurso da língua com conotações expressivas ou exerceram algum tipo de trabalho simbólico com a linguagem a fim de marcarem uma posição identitária. Avaliamos a maneira como as mulheres se orientaram em relação ao seu falar e ao dos seus interagentes e observamos se algum recurso da língua se destacou a tal ponto de ser alvo de julgamentos que pudessem revelar alguma ideologia ou posicionamento. (VELOSO, 2017, p. 237)

Então, apesar de não eleger uma variante, - fônica, lexical, mórfica, sintática ou semântica - a autora compreende que todos os níveis da língua podem se fazer presentes na fala das mulheres lésbicas, além disso, a terceira onda, como já mencionado, está mais interessada na prática linguística do que na estrutura linguística. Portanto, essa tendência busca pelo seguinte: “[...] o significado social na prática estilística, compreendendo que a construção de uma persona/identidade, fundamento essencial ao posicionamento do indivíduo no meio social, depende de uma agentividade linguística que é perpassada pela forma como o sujeito conduz os estilos" (VELOSO, 2014, p. 1746). Para exemplificar dados, o quadro abaixo:

Quadro 01 - Conversa entre mulheres lésbicas

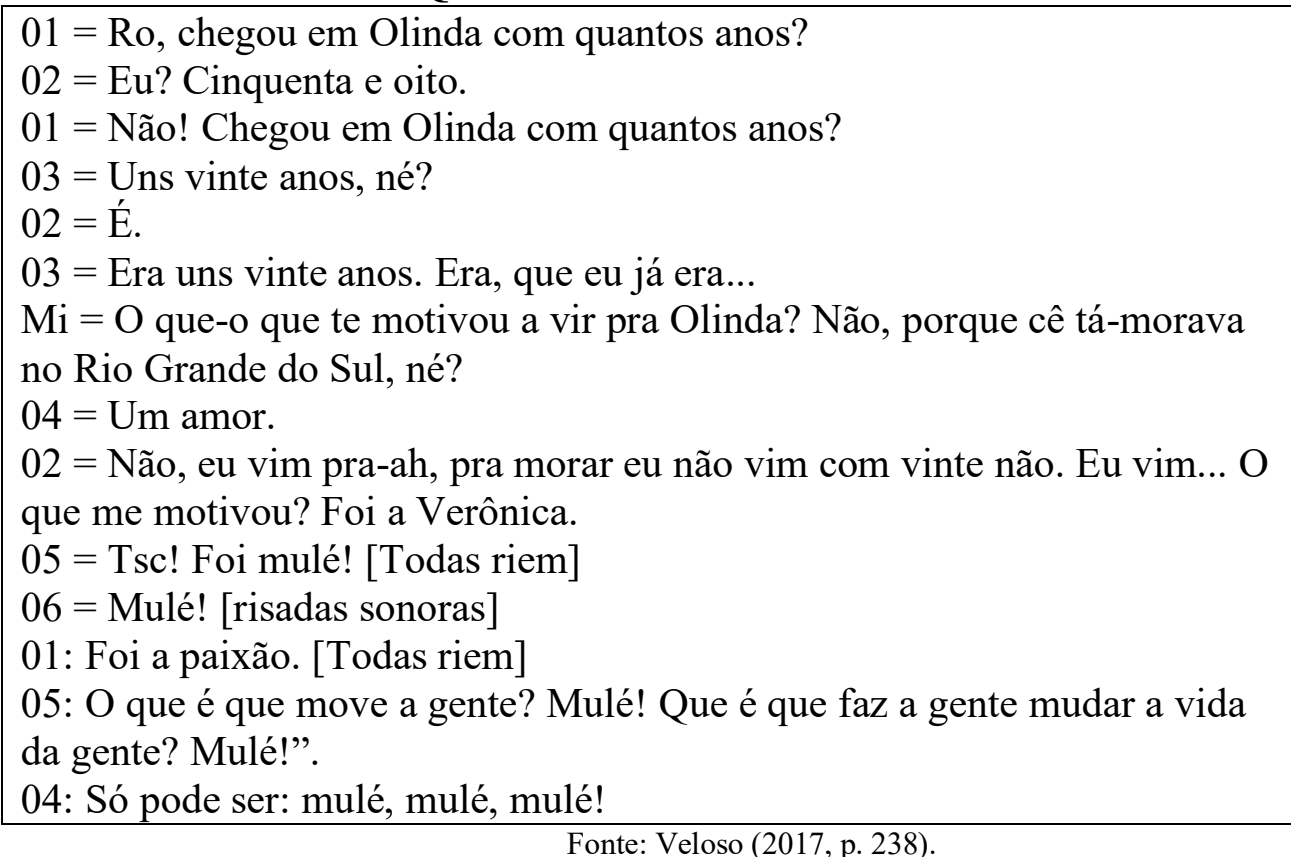

Conforme Veloso (2017), a escolha do item linguístico "mulé" é bastante emblemático, pois demonstra um interesse afetivo/amoroso/sexual que é compartilhado por todas, enquanto 
Volume 16 - Número 1 - jan/jul de 2021

mulheres lésbicas. Contudo, esse uso não pode ser interpretado apenas pela correlação de fatores linguísticos e sociais, como geralmente indicariam as análises tradicionais, uma vez que é uma realização intencional tanto para dar um tom de brincadeira, já que foi dita em tom de gracejo, como para performar uma persona. Além disso, a autora, acrescenta que o efeito de riso acionado pelo item "mulé" sugere que há alguma associação com o contexto lésbico, pois o sentido interpretado na conversa aciona uma informação específica que é compartilhada entre as interlocutoras e indica relevância social para elas.

Assim, o significado do termo ecoa entre as amigas porque elas associam seu uso a alguma prática ou conhecimento que faz parte de suas vivências, como explica Veloso (2017). Essa investigação é possível porque interessa-se por outros significados que não os de primeira ou segunda onda e centraliza seu olhar numa visão mais vertical. Afinal, caso não considerasse o contexto de uso do item "mulé" e analisasse o termo sob outra perspectiva teóricometodológica, provavelmente, seu potencial expressivo seria irrelevante, bem como não teria significância, como indica Veloso (2017) e acrescenta: "tal uso seria contabilizado, quem sabe, somente como uma ocorrência não-padrão da língua” (VELOSO, 2017, p. 239).

\section{Considerações finais}

Acredita-se que este trabalho tenha alcançado seu objetivo, uma vez que propôs analisar dados de pesquisas já concluídas com a finalidade de explicar como cada onda dos estudos sociolinguísticos variacionistas se interessa pela variável sexo/gênero. Nesse sentido, foi possível identificar que a primeira onda é um estudo de larga escala que controla a variável em categorias fechadas e com cédulas binarias limítrofes, para que possa ter maior controle estatístico da variante em análise. Já a segunda onda é de caráter etnográfico, mas que também lança mão de análise estatística, considerando o controle da variável a partir do locus de investigação, o que necessita de maior controle da variável sem perder de vista o contexto de realização da variante e a dinâmica social da variável. E, a terceira onda centraliza a prática linguística, indo além das variantes linguísticas, uma vez que se interessa pelo significado social associado às variantes que compõem o estilo dos/as falantes de comunidades de prática em específico.

Salienta-se, junto a Veloso (2014), que os estudos de cada onda não se anulam ou se negam um sob o outro, somente correspondem a distintos percursos teórico-metodológicos ao lidar com a variação linguística ao longo das décadas de investigação. Isso indica como a área é ampla e aberta para as contribuições produtivas que potencializem o estudo da variação linguística em sentido macro ou micro. É importante ressaltar que cada onda tem suas limitações, mas apresenta contribuições distintas e relevantes para a compreensão dos fenômenos que envolvem a língua em uso. Exposto isso, espera-se que o texto contribua para os/as interessados/as na variável sexo/gênero, nos estudos sociolinguísticos de forma geral e para a compreensão das três ondas de investigação.

\section{Referências}

ABAURRE, M. B. M. Entrevista com Maria Bernadete Marques Abaurre. In: XAVIER, Antonio Carlos; CORTEZ, Suzana (org.). Conversa com linguistas: virtudes e controvérsias da linguística. São Paulo: Parábola Editorial, 2006, p. 13-24.

ANDRADE, A. de O.; SANTOS, L. P. M. Feminismo, gênero e seus (des)caminhos: nuances de uma epistemologia sócio-histórica. In: ANDRADE, A. de O. et al (org.). Feminismo, gênero e sexualidade: diálogos contemporâneos. Mossoró: Edições UERN, 2016, p. 21-48. BAGNO, M. Dicionário crítico de Sociolinguística. São Paulo: Parábola Editorial, 2017. BAGNO, M. Nada na Língua é por acaso: por uma pedagogia da variação linguística. São Paulo: Parábola Editorial, 2007. 
Volume 16 - Número 1 - jan/jul de 2021

BORTONI-RICARDO, S. M. Do campo para a cidade: estudo sociolinguístico de migração e redes sociais. Tradução de Stella M. Bortoni-Ricardo e Maria do R. R. Caxangá. São Paulo: Parábola Editorial, 2011.

COELHO, R. F. É nóis na fita! Duas variáveis linguísticas numa vizinhança da periferia paulistana. 2006. 182 f. Dissertação (Mestrado em Linguística) - Universidade de São Paulo, São Paulo.

ECKERT, P.; MCCONNELL-GINET, S. Comunidades de práticas: lugar onde co-habitam linguagem, gênero e poder. Tradução de Branca Falabella Babricio. In: OSTERMANN, A.

C.; FONTANA, B. Linguagem, gênero e sexualidade: clássicos traduzidos, São Paulo: Parábola Editorial, 2010, p. 93-107.

FREITAG, R. M. K. (Re)Discutindo Sexo/Gênero na Sociolinguística. In: FREITAG, R. M. K.; SEVERO, C. G. (org.). Mulheres, Linguagem e Poder - Estudos de Gênero na Sociolinguística Brasileira. São Paulo: Blucher, 2015, p. 17-74.

LABOV, W. Padrões Sociolinguísticos. Tradução de Marcos Bagno, Maria Marta P. Scherre e Caroline R. Cardoso. São Paulo: Parábola Editorial, 2008.

LAKOFF, R. Linguagem e lugar da mulher. Tradução de Adriana Braga e Édison Luis Gastaldo. In: OSTERMANN, A. C.; FONTANA, B. Linguagem, Gênero e Sexualidade: clássicos traduzidos. São Paulo: Parábola Editorial, 2010, p. 13-30.

LOURO, G. L. Um corpo estranho: ensaios sobre sexualidade e teoria queer. 3. ed. Belo Horizonte: Autêntica, 2020.

MOLLICA, M. C. Fundamentação teórica: conceituação e delimitação. In: MOLLICA, M. C.; BRAGA, M. L. Introdução à Sociolinguística: o tratamento da variação. 4. ed. São Paulo:

Contexto, 2015, p. 09-14.

MONTE, A. A influência da escolaridade e do sexo/gênero no uso variável da concordância verbal de terceira pessoa do plural. Revista Diálogos. v. 7, n. 1, 2019, p. 89-104.

PAIVA, V. L. M. de O. e. Manual de pesquisa em estudos linguísticos. São Paulo: Parábola Editorial, 2019.

SILVA, A. L. S. da. O pajubá no ENEM: preconceito e diversidade linguística. 2020. 68 f. Monografia (Especialização em Ensino de Línguas e Literaturas na Educação Básica) Universidade Estadual da Paraíba, Guarabira.

VELOSO, R.. As três ondas da Sociolinguística e um estudo em comunidades de práticas. In: XVII Congreso Internacional Asociación de Lingüística y Filología de América Latina. João Pessoa: Ideia, 2014, p. 1740-1749.

VELOSO, R. Sobre as novas tendências da pesquisa sociolinguística: um estudo sobre variação estilística. In: XXVI Jornada do Grupo de Estudos Linguísticos do Nordeste. Recife: Pipa Comunicação, 2017, p. 231-242. 